EPJ Web of Conferences 45, 01126 (2013)

DOI: $10.1051 /$ epjconf/20134501126

(C) Owned by the authors, published by EDP Sciences, 2013

\title{
The impacts of cooling construction on the ability distract the heat of condensation part of the heat pipe
}

\author{
A. Čaja ${ }^{1, a}$, P. Nemec ${ }^{1}$, M. Malcho ${ }^{1}$, and S. Gavlas ${ }^{1}$ \\ University of Žilina, Faculty of Mechanical Engineering, Department of Power Engineering, Univerzitná 1, 01026, \\ Žilina, Slovakia
}

\begin{abstract}
Heat pipes as cooling devices have a high potential. Their power to affect a variety of factors - the vapour pressure, the amount of media work etc. It is therefore necessary to verify the calculated parameters also practically. To determine the performance of transmitted heat pipe is the best calorimetric method. When it is out of the flow and the temperature difference the cooling part of the heat pipe determines its transmitted power. The contribution is focused on comparison of two types of coolers. The first type is looped capillary cooler for the condenser section. The small diameter capillary is secured high coolant turbulence and hence heat dissipation. The second type is non-contact cooling, where cooling fluid washes direct heat pipe wall.
\end{abstract}

\section{Introduction}

Heat pipe is a device that is used for quick and effective heat transfer because they have very low thermal resistance. Heat is transferred by working fluid vapor from warmer place (evaporator) to cooler (condenser). The advantage of heat pipes is their small size and great power outputs for transport, long service life (min. 20 years) and maintenance free operation (with the possible exception of cleaning the external heat transfer surfaces). Gravitational heat pipes operate almost with unchanged effect at angles of inclination of $15^{\circ}$ to $90^{\circ}$ from the horizontal.

Heat pipes can be as the evaporating section and the condenser bearing extension that increases the surface space heat transfer to the evaporator and condenser, thus reducing the thermal resistance of flow and heat dissipation. Increased size of the capacitor has a positive impact on the long-term conservation of thermal properties of the heat pipe.

Heat pipes are made for different transmitted powers and operating temperatures. Working temperature of the heat pipe depends mainly achieved vacuum created in its production.

Working temperature, i.e., the temperature at which the working fluid begins to boil, the set amount of pressure within the heat pipe. If you will talk about the pressure, the pressure is absolute, that is calculated from scratch. This value is around $101 \mathrm{kPa}$. As surely everyone knows, the boiling point of a liquid is the pressure dependent. Example in the water which may be in heat pipes also be used as a working medium, is at atmospheric pressure of $100{ }^{\circ} \mathrm{C}$ The heat pipe, encountered in computers can use water as the working substance. The following table describes the dependence of the boiling point of the water in the absolute pressure.

Tab.1. The dependence the boiling point on the pressure.

\begin{tabular}{|l|c|c|c|c|}
\hline Boiling point $\left[{ }^{\circ} \mathrm{C}\right]$ & 0.01 & 5 & 10 & 15 \\
\hline Pressure $[\mathrm{kPa}]$ & 0.61 & 0.87 & 1.23 & 1.71 \\
\hline Boiling point $\left[{ }^{\circ} \mathrm{C}\right]$ & 20 & 25 & 30 & 35 \\
\hline Pressure $[\mathrm{kPa}]$ & 2.34 & 3.17 & 4.25 & 5.63 \\
\hline Boiling point $\left[{ }^{\circ} \mathrm{C}\right]$ & 40 & 45 & 50 & 55 \\
\hline Pressure $[\mathrm{kPa}]$ & 7.38 & 9.59 & 12.35 & 15.76 \\
\hline Boiling point $\left[{ }^{\circ} \mathrm{C}\right]$ & 60 & 65 & 70 & 75 \\
\hline Pressure $[\mathrm{kPa}]$ & 19.95 & 25.04 & 31.20 & 38.60 \\
\hline Boiling point $\left[{ }^{\circ} \mathrm{C}\right]$ & 80 & 85 & 90 & 95 \\
\hline Pressure $[\mathrm{kPa}]$ & 47.41 & 57.87 & 70.18 & 84.61 \\
\hline Boiling point $\left[{ }^{\circ} \mathrm{C}\right]$ & 100 & 105 & 110 & 115 \\
\hline Pressure $[\mathrm{kPa}]$ & 101.42 & 120.90 & 143.38 & 169.18 \\
\hline Boiling point $\left[{ }^{\circ} \mathrm{C}\right]$ & 120 & 125 & 130 & 135 \\
\hline Pressure $[\mathrm{kPa}]$ & 198.67 & 232.22 & 270.26 & 313.20 \\
\hline
\end{tabular}

View of the above table it is clear that the heat pipe of the same material and the same working substance might not have the same heat transfer characteristics to be produced on a variety of pressure and thus for different temperatures. In order to determine the actual transmitted flow by heat pipe is necessary to make further measurements. In terms of heat transfer appears to be the best calorimetric method. In this method, the evaporation

alexander.caja@fstroj.uniza.sk,phone n.: +421415132863, fax n.: +421415252541 
of the heat pipe heated constant heat source, whose output we know. Condensation of the heat pipe is cooled with liquid for which we know the initial temperature, the final temperature and the flow rate. For this purpose built two types of coolers.

\section{The Capillary cooler}

The first type is the capillary cooler. It's basically a small diameter capillary tightly wound on the condensation of the heat pipe. To ensure better contact capillary cooler with the heat pipe was condensation of the coated with thermal compound. Given that it is a capillary tube of small diameter, it is considered that in the cooler is the turbulent flow and therefore a good heat removal from the condensation section. To avoid losses to the surroundings, the entire cooler with adiabatic uncovered part of the heat pipe thermal insulation wraps.

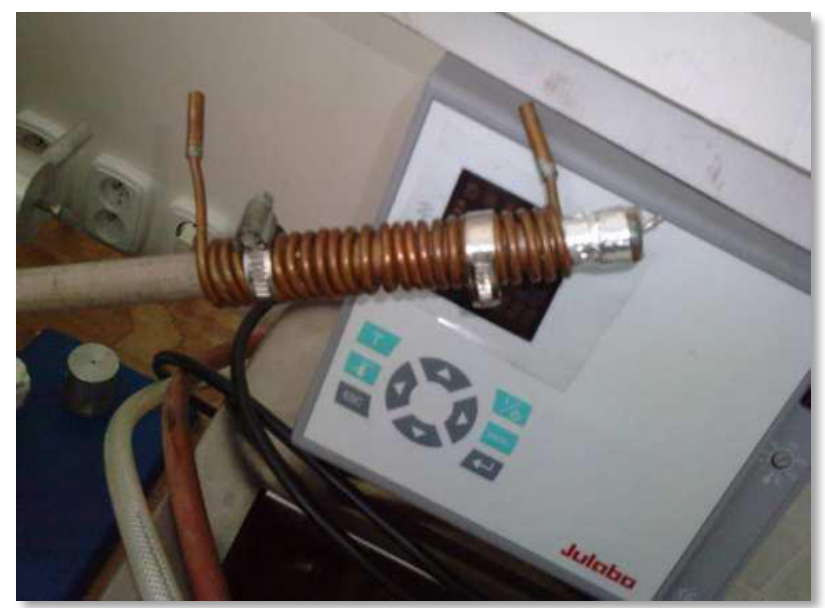

Fig.1. The capillary cooler.

\section{The pipe cooler}

The second type is the tubular cooler. It is basically a copper pipe from one side closed. A second open side is used for inserting the measured heat pipes. At the top of the cooler is designed for coolant inlet and outlet at the bottom of the liquid. The advantage of this cooler is that it eliminates wall and coolant washes direct heat pipe surface. Inlet and outlet coolant is positioned so as to ensure the flow of coolant the helix-shaped around condensation of the heat pipe. As with the first type of cooler is also in this case the entire cooler with adiabatic section of heat pipe heat insulated from the action of the external environment

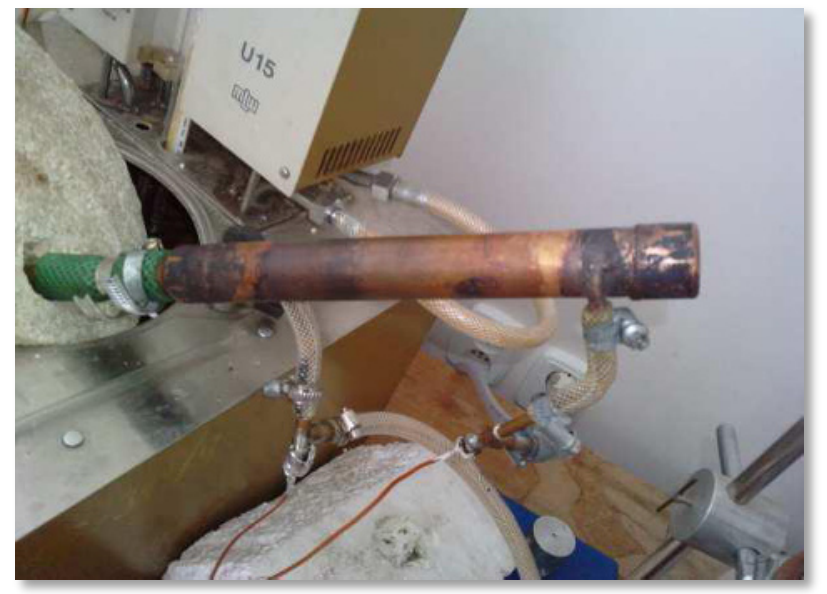

Fig.2. The pipe cooler.

Both coolers are then connected to an ultrasonic flow meter KAMSTRUP that our senses coolant flow rate. Temperatures were measured by thermocouples and recorded by measuring the control panel to the computer.

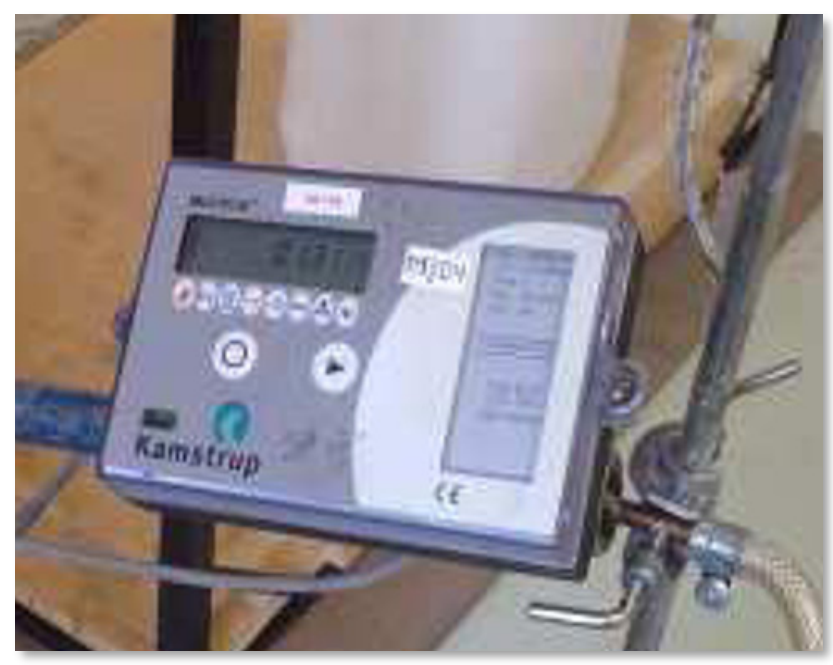

Fig.3. The flow meter KAMSTRUP.

Coolant supplied circulatory thermostat JULABO. Heating evaporating section was solved using a second circulating thermostat. Heating but can be ensured by means of resistance wire, which can be clearly defined input current and voltage and the output is determined. In this case, it must be thermally insulated evaporation of the heat pipe, too. 


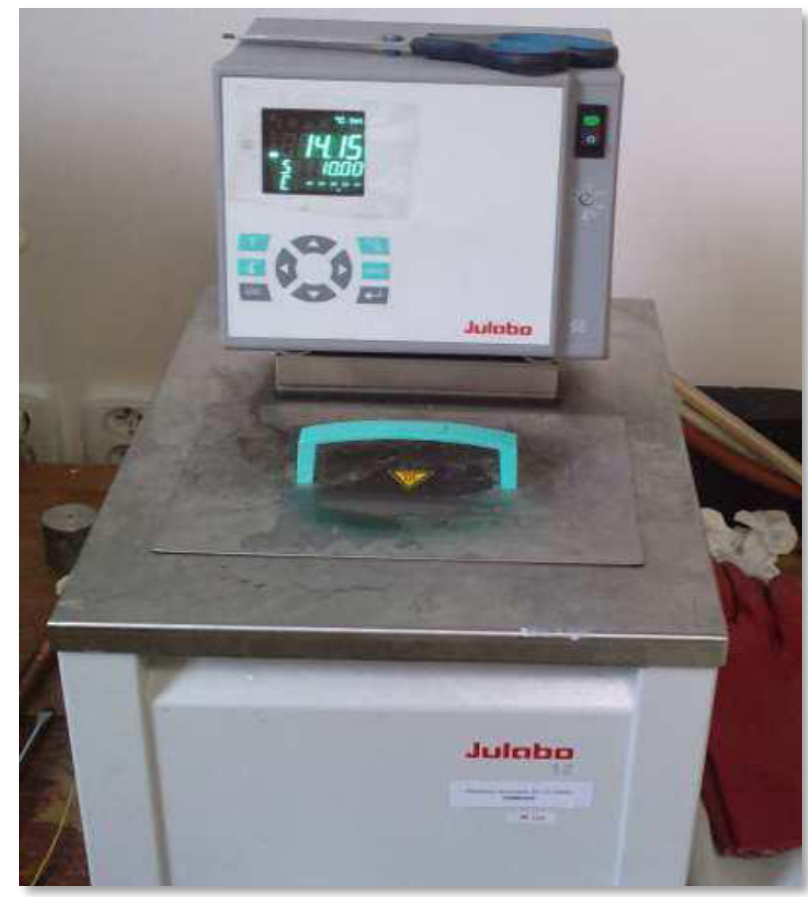

Fig.4. The thermostat JULABO.

The activities of these two coolers are tested on three different heat pipes - gravitational heat pipe filled with alcohol and two thermal capillary tubes filled with water and acetone. The measurement procedure was for all three heat pipes the same as they were made for about the same temperature range. The first flow thermostat water bath was heated to the desired temperature. After reaching this temperature, thermal insulated and ready to put a tube into the bath and watched the process temperature. After stabilization of inlet and outlet temperature on the heat sink, the measurement was completed.

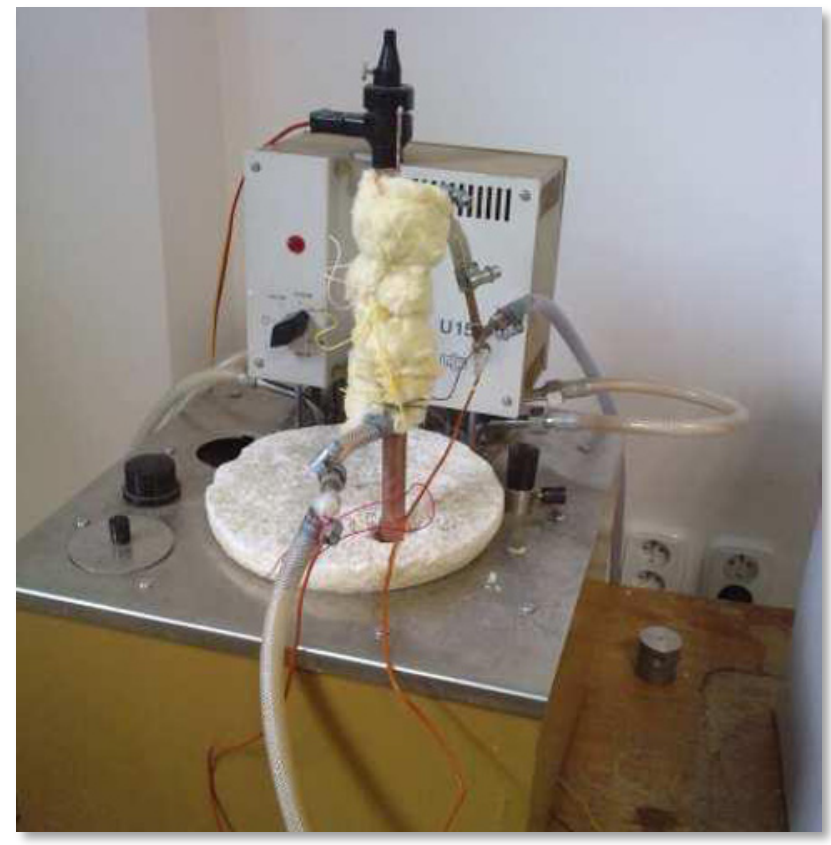

Fig.5 The heat pipe ready to measure.
Temperature of heat pipe evaporator section was measuring with $\mathrm{NiCr}-\mathrm{Ni}$ thermocouple set at the inlet and outlet of the cooling on heat pipe. Measurement of thermal performance of heat pipes was at vertical position and temperature of heat source $50{ }^{\circ} \mathrm{C}$ and $70^{\circ} \mathrm{C}$. Heat performance solution of heat pipe is based on calorimetrical equation and values from experimental measuring. The same calculations were used at work [11].

$$
\begin{aligned}
& Q=m \cdot c \cdot \Delta t \\
& \Delta t=t_{2}-t_{1}
\end{aligned}
$$

Where is $\Delta \mathrm{t}\left[{ }^{\circ} \mathrm{C}\right]$ - temperature difference, $\mathrm{t}_{1}\left[{ }^{\circ} \mathrm{C}\right]-$ input temperature, $\mathrm{t}_{2}\left[{ }^{\circ} \mathrm{C}\right]-$ output temperature, $\dot{m}\left[\mathrm{~J}^{\circ} \mathrm{kg}^{-1} \cdot \mathrm{K}^{-1}\right]$ - mass flow of liquid, c $\left[\mathrm{J} \cdot \mathrm{kg} \cdot \mathrm{s}^{-1}\right]$ - special thermal capacities of liquid.

\section{The temperature dependence of the time - heat pipe filled with assetone and pipe cooler}

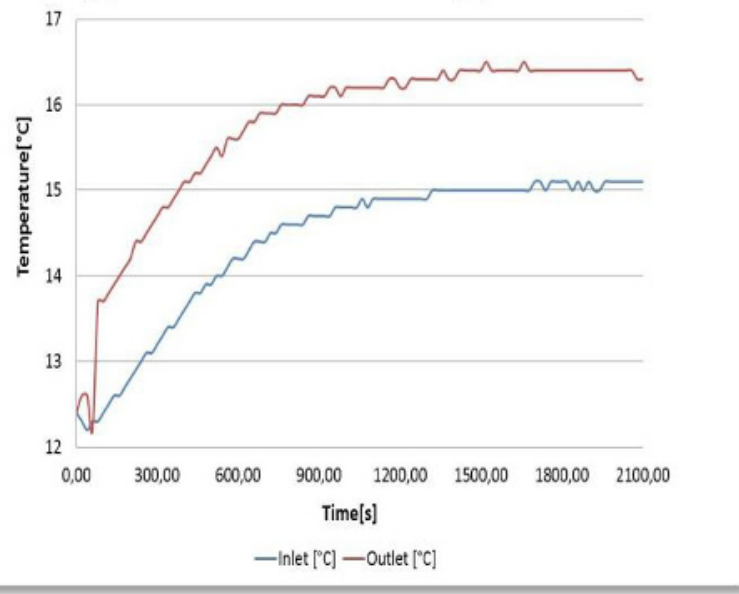

Fig.6. The developments depending on the time.

Based on the measured and calculated values were determined transmitted thermal performance of heat pipes and the ability to dissipate heat for cooler designed. Calculated values are shown in the table.

Tab.2. The measured variables.

\begin{tabular}{|l|l|l|l|l|l|l|}
\hline Cooler & Pipe & $\begin{array}{l}\text { Capil } \\
\text { lary }\end{array}$ & Pipe & $\begin{array}{l}\text { Capil } \\
\text { lary }\end{array}$ & Pipe & $\begin{array}{l}\text { Capil } \\
\text { lary }\end{array}$ \\
\hline $\begin{array}{l}\text { Heat } \\
\text { pipe }\end{array}$ & \multicolumn{2}{|c|}{ With acceton } & \multicolumn{2}{|c|}{ Vith watter } & \multicolumn{2}{|c|}{ With alcohol } \\
\hline $\begin{array}{l}\text { Temper } \\
\text { ature } \\
\text { differen } \\
\text { ce } \Delta \mathrm{t} \\
{\left[{ }^{\circ} \mathrm{C}\right]}\end{array}$ & 1.34 & 9.92 & 2.33 & 7.18 & 1.86 & 6.76 \\
\hline $\begin{array}{l}\text { Flow } \\
\text { rate }^{\left[1 . \text { hod }^{-1}\right]}\end{array}$ & $\begin{array}{c}113 . \\
5\end{array}$ & 13.2 & 78.1 & 13.1 & 95.9 & 13.1 \\
\hline
\end{tabular}




\begin{tabular}{|l|c|c|c|c|c|c|}
\hline $\begin{array}{l}\text { Mass } \\
\text { flow } \\
{\left[\mathrm{m}^{3} \cdot \mathrm{s}^{-1}\right]}\end{array}$ & $\begin{array}{c}3.15 . \\
10^{-5}\end{array}$ & $\begin{array}{c}3.66 . \\
10^{-6}\end{array}$ & $\begin{array}{c}2.17 . \\
10^{-5}\end{array}$ & $\begin{array}{c}3.63 . \\
10^{-6}\end{array}$ & $\begin{array}{c}2.66 . \\
10^{-5}\end{array}$ & $\begin{array}{c}3.63 . \\
10^{-6}\end{array}$ \\
\hline $\begin{array}{l}\text { Power } \\
{[\mathrm{W}]}\end{array}$ & $\begin{array}{c}176 . \\
2\end{array}$ & $\begin{array}{c}152.0 \\
3\end{array}$ & $\begin{array}{c}211 . \\
84\end{array}$ & $\begin{array}{c}108.9 \\
7\end{array}$ & $\begin{array}{c}207 . \\
77\end{array}$ & $\begin{array}{c}102.3 \\
5\end{array}$ \\
\hline
\end{tabular}

\section{Conclusion}

The measured values show that tubular radiator can distract from the larger heat pipe thermal performance as well as the capillary for a long time under the same conditions of measurement. Exhaust heat were higher by $105.4 \mathrm{~W}$ in the spirit of gravity heat pipe, a difference of $103 \%$ compared to the amount of dissipation of capillary condenser. For thermal capillary tube was filled with acetone condenser, tubular exhaust heat of $24.2 \mathrm{~W}$ more which is $15.9 \%$ more compared to capillary radiator for heat dissipation of the heat pipe. The capillary tube filled with water heat pipe cooler did a $102.9 \mathrm{~W}$ capillary more heat than what a family of $94.4 \%$. It follows that even if the capillary cooling achieved by turbulent flow, there is still the ability to dissipate heat from the heat pipe quite a bit smaller than the pipe cooler. The only advantage for cooling the capillary is that it can be easily fitted to the condensation part thereof without the need to open or: otherwise manipulate heat pipe, where it would be contained in a heat pipe unit. The disadvantage is lower accuracy compared to pipe cooler. Pipe cooler has the advantage of simple structure and higher thermal power dissipated through direct contact with the coolant heat pipe wall.

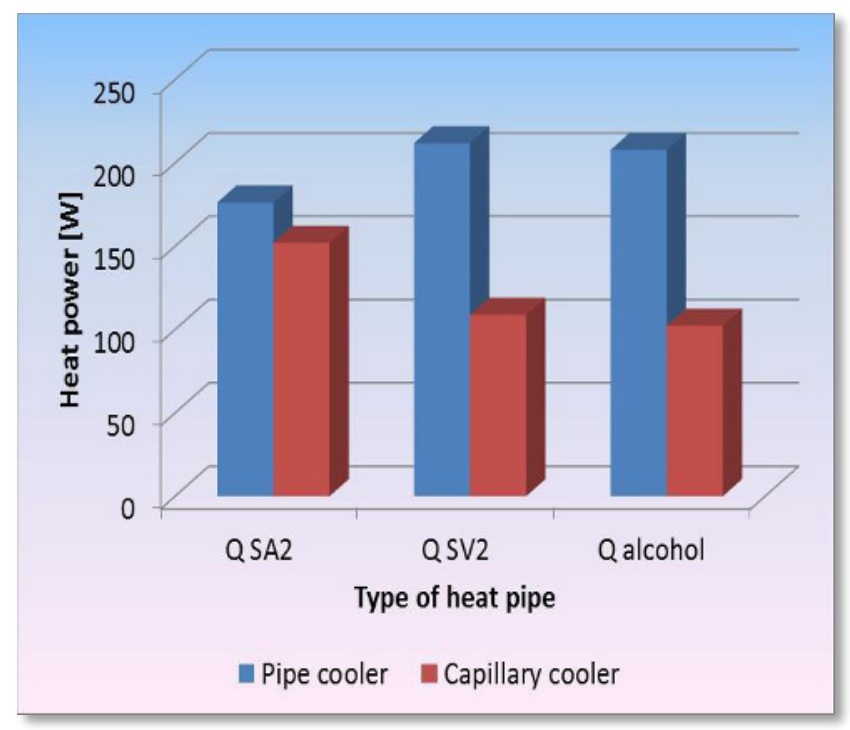

Fig.7. The amount of heat loss, depending on the cooler used.

\section{Acknowledgments}

This article was created within the frame of project APVV - $0448-07$

This article was created within the frame of project KEGA 064ŽU-4/2012

\section{References}

1. Jay M., Ochterbeck: Heat Transfer Handbook, 1. Edition, (2003)

2. R. S. Gaugler: Heat transfer devices, (1944)

3. Grover, G. M., Cotter, T.P. Erikson, G.F.: Structures of very high thermal conductivity, J. Appl. Phys. (1964)

4. A. Kapjor, R. Lenhard, Z. Horváth, TRANSCOM 7, 101-104 (2007)

5. A. Kapjor, A. Kosecová, Š. Papučík, TRANSCOM 6, 69-72 (2005)

6. J. Hužvár, J. Jandačka, A. Oksanen, Optimization using exergy-based methods and computational fluid, 219-224 (2009)

7. R. Lenhard, Power control and optimization, (2010)

8. R. Nosek, J. Jandačka, A. Szlek, Experimental fluid mechanics, 247-256 (2009)

9. P. Pilát, J. Mičicová, TRANSCOM 8, 117-119 (2009)

10. J. Jandačka, R. Nosek, Š. Papučík, Vykurovanie 2, 132-137 (2011) 